\title{
ASO Visual Abstract: Blood Vessel Invasion Predicts Postoperative Survival Outcomes and Systemic Recurrence Regardless of Location or Blood Vessel Type in Patients with Lung Adenocarcinoma
}

Goeun Lee, MD ${ }^{1}$, Shinkyo Yoon, $\mathrm{MD}^{2}$, Bokyung Ahn, MD, $\mathrm{PhD}^{1}$, Hyeong-Ryul Kim, MD, $\mathrm{PhD}^{3}$, Se Jin Jang, MD, PhD ${ }^{1}$, and Hee Sang Hwang, MD, PhD ${ }^{1}$

${ }^{1}$ Department of Pathology, Asan Medical Center, University of Ulsan College of Medicine, Seoul, Republic of Korea; ${ }^{2}$ Department of Oncology, Asan Medical Center, University of Ulsan College of Medicine, Seoul, Republic of Korea; ${ }^{3}$ Department of Chest surgery, Asan Medical Center, University of Ulsan College of Medicine, Seoul, Republic of Korea

Regardless of the location or type of involved blood vessels, blood vessel invasion can predict systemic recurrence rate and survival outcomes in surgically resected lung adenocarcinoma (https://doi.org/10.1245/s10434-02110122-x).
DISCLOSURE The authors declare no conflicts of interest.

Publisher's Note Springer Nature remains neutral with regard to jurisdictional claims in published maps and institutional affiliations.

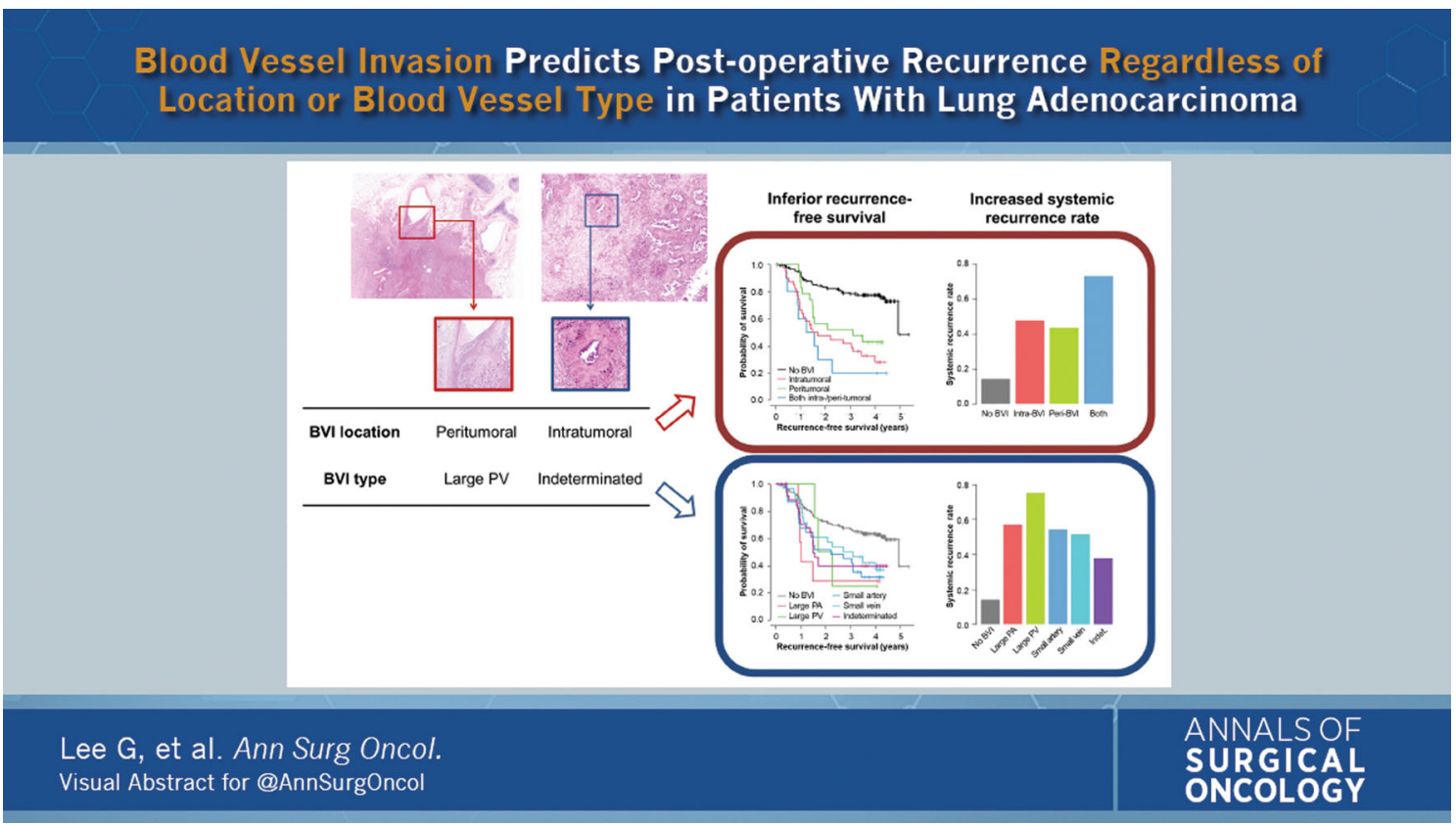

(C) Society of Surgical Oncology 2021

First Received: 19 April 2021;

Published Online: 23 June 2021

H. S. Hwang, MD, PhD

e-mail: hshwang0908@amc.seoul.kr; eldersage@empas.com 